\title{
Awareness of Pap test among women at a tertiary center in Bangalore, India
}

\author{
Megha Prakash, ${ }^{1}$ G.S. Jyothi, ${ }^{2}$ N.S. Murthy ${ }^{3}$
}

Keywords: Cervical cancer, Papanicolaou test, tertiary care center, awareness

\begin{abstract}
:
Introduction: In India, cervical cancer is the most common woman-related cancer, killing 1 woman every 8 minutes. Cervical cancer is more common in women who do not have a Pap test regularly. Secondary prevention achieved through Pap smear testing is the single most effective tool in reducing deaths due to cervical cancer. Scores of women in India fail to carry out this important test till today. In spite of the high incidence of cervical cancer reported from India, to the best of our knowledge, studies on assessing the knowledge and attitude of this test among women has been scanty. Hence, this study has been undertaken.
\end{abstract}

Objective: The aims of this study are to explore the knowledge of Pap test among women and the association between symptomatology and reasons for availing the Pap test.

Methods: The study was performed among 251 women aged between 20 and 65 years. The data was collected through a questionnaire containing their personal details and knowledge of the test. The same was tabulated.

Results: The study, conducted over a period of 2 months in a tertiary care urban center, revealed that $80.1 \%$ of the subjects were not even aware of the term "Cervical Cancer" and a mere 11.6\% were aware of the lifesaving Pap smear test. $36.6 \%$ of the subjects experienced one of the cardinal symptoms of cervical cancer while only $2 \%$ approached the doctor to avail the test. The remaining underwent it on recommendation by the doctor.

Conclusion: This study will increase awareness of the Pap test and cervical cancer, thereby paving a way for the prevention of cancer of the cervix.

${ }^{1}$ M.S. Ramaiah Medical College, Bangalore 560054, India

${ }^{2}$ Department of Obstetrics and Gynaecology, M.S. Ramaiah Medical College, Bangalore 560054, India

${ }^{3}$ Department of Community Medicine, M.S. Ramaiah Medical College, Bangalore 560054, India

\section{Introduction}

In India, cervical cancer is the most common woman-related cancer, killing 1 woman every 8 minutes. About 530,232 women are affected by cervical cancer in the world and about 275,008 succumb to this disease. ${ }^{1}$ According to the National Cancer Registry Program by Indian Council of Medical Research

Please cite this paper as: Prakash M, Jyothi GS, Murthy NS. Awareness of Pap test among women at a tertiary center in Bangalore, India. Proceedings in Obstetrics and Gynecology, 2015;5(1):Article 1 [ 8 p.]. Available from: http://ir.uiowa.edu/pog/. Free full text article.

Corresponding authors: Megha Prakash, Final year Medical student, M.S. Ramaiah Medical College, Bangalore 560054, India, megha prax@hotmail.com; Dr. Jyothi G.S., Professor, Department of Obstetrics and Gynaecology, M.S. Ramaiah Medical College, Bangalore 560054, India, (M):+91-9845257772, (R): 080-23484422, driyothigirish40@yahoo.co.in

Copyright: (c) 2015 Prakash et al. This is an open-access article distributed under the terms of the Creative Commons Attribution License, which permits unrestricted use, distribution, and reproduction in any medium, provided the original author and source are credited. 
(ICMR) in the year 2007, about 132,082 are affected by cancer of the cervix every year in India and 74,118 die of the disease. According to a recent study the burden of cancer of the cervix is increasing in India. There were 96,156 cases detected in the year 2011 and the estimated number of cases for the year 2026 is expected to be $148,813 .^{2}$ A study conducted in Bangalore, where a questionnaire was designed to tap the information about cancer of the cervix, its awareness and symptomatology and also about the Pap test among urban women and students, found that $29.55 \%$ of students and $19.07 \%$ of urban women did not know about the cervix, $79.55 \%$ students and $74.15 \%$ of urban women did not know about the symptoms of cervical cancer while $34.09 \%$ of students and $38.98 \%$ of women did not know about the Pap test. ${ }^{3}$ Almost 20$60 \%$ of all cervical cancer deaths could be avoided by improving screening programs. ${ }^{4}$ Countries like Sweden and Finland are reported to have the lowest incidence and prevalence of cervical cancer and related mortality and morbidity in the world. ${ }^{5,6}$ They have achieved this through excellent national screening programs which aim at increasing the awareness of Pap smear test amongst their women.

In studies done in African countries like Nigeria, Uganda and Botswana and also in countries like India and Thailand, women have been shown to have negative attitudes towards cancer of the cervix and the Pap smear screening programmes. ${ }^{7}$ Hence, this contributes to their non-participation in screening programs and even though screened do not follow up for further management even if an abnormality is detected.

Early age at initiation of sexual activity, multiple sex partners, no Pap-smear screening, lack of access to healthcare, lack of follow up and treatment facilities are among the major risk factors for the development of cervical cancer. India ranks fourth worldwide in the incidence of cervical cancer and this will not change until women are made aware of this important test. Scores of women fail to carry out this important test till today. In spite of the high incidence of cervical cancer reported from India, to the best of our knowledge, studies assessing the knowledge and attitude toward this test among women have been scanty. ${ }^{8}$ Hence, this study has been undertaken to evaluate awareness of cervical cancer and the Pap test while also providing appropriate education to women participating in this study, thereby paving a way for prevention of cervical cancer.

\section{Material and Methods}

A. Aim: The main aims of this study were to assess the knowledge of the Pap test among women aged 20 to 65 years and also to find out an association between symptomatology and reason for availing the Pap test.

B. Inclusion: Sexually active women between 20 and 65 years of age.

Exclusion: Women who have undergone hysterectomy.

C. Data collection: The study was conducted among women attending the Obstetrics and Gynaecology OPD at a tertiary care hospital in Bangalore, India. It was conducted from April 2013 to June 2013. All the consecutive 251 women who underwent the Pap test were interviewed after obtaining verbal consent from the patient. Ethical 
clearance was obtained from the Ethical Review Board of M.S. Ramaiah Medical College and Hospitals. A pre-tested and pre-designed questionnaire was employed and translated to the colloquial language to collect the entire information from the patient. The content validation was done by taking opinion of experts from the Department of Obstetrics and Gynaecology and Community Medicine. It consisted of identification particulars, sociodemographics, knowledge of the Pap test and also information on clinical symptomatology. The details were elicited through interview technique. The respondents answered freely and were counselled regarding the disease and importance of the Pap test. Confidentiality was maintained by not revealing the name of the participants. All the women were interviewed in separate rooms.

D. Data Analysis: Data were entered in Microsoft Excel and analyzed using SPSS version 17. All the quantitative variables were expressed in terms of mean and standard deviation. All the qualitative variables[E.g. religion]were expressed as percentage of total number of women studied. Chi Square test of significance was employed to test whether there was any association between symptomatology and the reason for availing the test. Probability value less than 0.05 was considered statistically significant.

\section{Results}

The first part of the questionnaire dealt with the personal details of the subjects such as their place of residence, age (Table 1), education, occupation, marital status and parity.
Table 1. Age distribution of study participants

\begin{tabular}{lll}
\hline Age (in years) & Frequency & Percentage \\
\hline $\mathbf{2 0 - 2 4}$ & 5 & 2 \\
$\mathbf{2 5 - 2 9}$ & 16 & 6.4 \\
$\mathbf{3 0 - 3 4}$ & 29 & 11.6 \\
$\mathbf{3 5 - 3 9}$ & 33 & 13.1 \\
$\mathbf{4 0 - 4 4}$ & 38 & 15.1 \\
$\mathbf{4 5 - 4 9}$ & 52 & 20.7 \\
$\mathbf{5 0 - 5 4}$ & 29 & 11.6 \\
$\mathbf{5 5 - 5 9}$ & 24 & 9.6 \\
$\mathbf{6 0}$ and above & 25 & 10 \\
\hline
\end{tabular}

Place of residence: 163 [64.9\%] participants were from urban areas, the participants from the rural background were about 82 [32.7\%] while the rest of them, 6 [2.4\%] did not reveal their place of residence.

Education: 118 [47\%] participants were college graduates while 69 [27.5\%] were high school graduates, 34 [13.5\%] had received vocational training and 12 [4.8\%] had completed primary level and 14 [5.6\%] had completed their secondary level of education respectively. 1 participant [0.4\%] was unaware of her educational qualifications and 3 [1.2\%] of them did not mention their educational background.

Occupation: 128 participants [51\%] were housewives while 121 [48.3\%] were engaged in some form of paid employment such as teaching jobs, manual workers, technical and office going. $2[0.7 \%]$ participating women did not reveal their occupation.

Marital Status: 236 [94\%] participants were married while 12 [4.8\%] were widowed. 3 [1.2\%] women were 
unmarried and the Pap test was conducted on them as they were above 40 years and gave a history of sexual contact.

Parity: The majority [46.6\%] of the women had 2 children.

The second part of the questionnaire dealt with knowledge of the Pap test and cervical cancer, awareness of the cardinal cervical cancer symptoms, present symptomatology of the subject and the reason for availing the Pap test.

Awareness of cervical cancer: 201 [80.1\%] women were not aware of the term "cervical cancer". 29 [11.6\%] were aware of this disease while 14 [5.6\%] of them had the misconception that cervical cancer was cancer of the uterus and 7 [2.8\%] of them thought it was cancer of the vagina (Table 2).

\section{Table 2. Awareness of cervical cancer}

\begin{tabular}{lll}
\hline Factors & Frequency & Percentage \\
\hline Cancer of uterus & 14 & 5.6 \\
Cancer of cervix & 29 & 11.6 \\
Cancer of Vagina & 7 & 2.8 \\
Don't know & 201 & 80.1 \\
Total & 251 & 100 \\
\hline
\end{tabular}

Awareness of the Pap smear Test: The results of the main objective of the study revealed that only 29 [11.6\%] participants were aware of the Pap test while 221 [88\%] were unaware of this life saving test (Table 3).

\section{Table 3. Awareness of the Pap test}

\begin{tabular}{lll}
\hline FACTORS & FREQUENCY & PERCENTAGE \\
\hline Cancer of cervix & 29 & 11.6 \\
Infection passed on during blood transfusion & 1 & 0.4 \\
Don't know & 221 & 88 \\
Total & 251 & 100 \\
\hline
\end{tabular}

Awareness of cervical cancer warning signals: This part of the study endeavored to assess the awareness of the cardinal cervical cancer warning signals such as excessive white discharge per vagina, lumps, bleeding between menstrual cycles and bleeding experienced post intercourse. Overall it revealed that 226 [90\%] subjects were unaware of the symptoms, while 23 [9.2\%] were aware of these symptoms and the remaining $2[0.8 \%]$ refused to comment.
Out of these four main symptoms 16 [6.4\%] women were aware that excessive white discharge per vagina is a sign of cervical cancer,13 [5.2\%] women were aware of lumps, 8 [3.2\%] women were aware that intermenstrual bleed is a warning signal and only 3 [1.2\%] women were aware that postcoital bleeding is a warning sign.

To determine the association between the symptoms experienced by the patient and the reason for undergoing 
the Pap test, a Chi square test of significance was employed to find out if there was any association. A proportion value of less than 0.05 was considered as statistically significant.

The patients were asked if they had experienced any of the above stated symptoms of cervical cancer, including lumps, white discharge, intermenstrual bleeding and bleed post intercourse, and what propelled them to undergo a Pap test at this time.

91[36.6\%] subjects had experienced one or more than one of the above signs but underwent the Pap test only on the recommendation of their doctor. Very few subjects, only 5 [2\%] of them, experienced these signs and approached the healthcare professionals, desiring to undergo this test.

140 [56.45\%] subjects revealed that they did not experience any symptoms but have undergone the test only because the doctor recommended it; while 11 [4.4\%] subjects underwent this test by their own desire without recommendation from the doctor or experiencing any signs. One participant [0.4\%] said she had not experienced any of the symptoms but still underwent the test because she felt the need to and also the doctor recommended. $3[1.1 \%]$ participants refused to provide the above details (Table 4).

Table 4. Association between symptoms experienced and reason for undergoing the Pap test

\begin{tabular}{|c|c|c|c|c|c|}
\hline \multirow{2}{*}{\multicolumn{2}{|c|}{ Symptoms experienced }} & \multicolumn{3}{|c|}{ Reason to undergo a pap test } & \multirow{2}{*}{ Total } \\
\hline & & \multirow{3}{*}{$\begin{array}{c}\begin{array}{c}\text { Doctor } \\
\text { recommended }\end{array} \\
91\end{array}$} & \multirow{3}{*}{$\frac{\text { Self referral }}{5}$} & & \\
\hline \multirow{3}{*}{ Yes } & Crunt & & & \multirow{2}{*}{$\frac{\text { Both }}{0}$} & \\
\hline & & & & & 50 \\
\hline & \% within signals experienced & $94.80 \%$ & $5.20 \%$ & $0.00 \%$ & $100.00 \%$ \\
\hline \multirow[t]{2}{*}{ No } & Count & 140 & 11 & 1 & 152 \\
\hline & \% within signals experienced & $92.10 \%$ & $7.20 \%$ & $0.70 \%$ & $100.00 \%$ \\
\hline \multirow[b]{2}{*}{ Total } & Count & 231 & 16 & 1 & 248 \\
\hline & \% of Total & $93.10 \%$ & $6.50 \%$ & $0.40 \%$ & $100.00 \%$ \\
\hline
\end{tabular}

\section{Discussion}

The data focuses on awareness of the basic Pap smear test among women visiting the OBG OPD, a tertiary care health center in Bangalore Metropolis. The result showed that only $11.6 \%$ were aware of this test and also about cervical cancer. The majority [94.8\%] of the women having this test were unaware of the actual purpose; hence, this explains the non-compliance of the subjects to return to the hospital upon detection of any abnormality. Due to these reasons, all the subjects who participated in this study were educated on the importance of this test and the need to immediately contact a doctor if they experienced any of the above symptoms. Selection bias has been ruled out in this study. We have reported all consecutive women in the hospital, 
who fulfilled the criteria. Information bias was ruled out. The female interviewer first developed a good rapport with the participant and then collected the information using the pilot tested and standard questionnaire evaluated by the experts. The average age of women interviewed was 43 years and most of them had no knowledge of cervical pathology, clearly indicating that none of them are aware of the fact that cervical cancer can be prevented by vaccination, which highlights the need for awareness programs for women in this age group. This knowledge will help them to seek vaccination for their daughters in the younger age group and thus help to curb the problem effectively in the coming generations. ${ }^{3}$

With regards to the attitude of women in availing the Pap test and the symptoms they present with, only $5.2 \%$ were aware that their perceived symptoms may have a susceptibility of developing into cancer and hence approached for a Pap smear screening. The remaining $94.8 \%$ in spite of experiencing the cardinal symptoms of cervical cancer did not know their perceived susceptibility to the disease as these were the women who were not aware of the Pap smear test. As a result, they will have a better chance of having advanced disease and greater mortality from cancer of the cervix. This study is not without limitations; because the participants came from a tertiary hospital in Bangalore, India, our findings may not be generalized to the entire geographic area.

Two studies of Asian women in North America-one of Asian women living in the US and one of Chinese women living in Canada-confirmed that Asian attitudes towards sexuality pose barriers to cervical cancer screening.,10
Another astonishing study in India, revealed that very few women in spite of being aware of the test, opted to have the test due to the absence of symptoms and apprehension that it detects cancer; while some who were willing could not have the test due to hurdles. The most common hurdles, bizarre to the western world, were inability to leave household chores, preoccupation with family problems and lack of approval from husbands. This highlights that modification of health behavior through education and social empowerment of women are essential for a population based cervical screening program to succeed in India. ${ }^{11}$ These may be trivial issues to the western world but it shows us that we have more challenges to overcome in order to achieve a high success rate in spreading the awareness to women. Various studies indicate that the media plays an important role in disseminating health education information. ${ }^{12}$ The authors show that the role of the media in disseminating health maintenance information should not be discounted. ${ }^{13}$ With this poor knowledge of the Pap test, a health education program which incorporates the media could be very impactful in our environment. The major findings in this study were a poor level of knowledge of cervical cancer, its symptomatology and the Pap test.

\section{Recommendations}

In view of all the findings and after discussion of the study, the following are recommended.

1. Awareness programs targeting women on cervical cancer and the Pap test should be initiated. This can be done with the help of media, doctors, nurses, etc. ${ }^{11}$ 
2. To provide mobile testing caravans to reach the women in remote villages.

3. The Ministry of Woman and Child Welfare should provide incentives for women to undergo this test.

4. Further research on the awareness of the newly introduced HPV vaccine and its compliance among women can be done.

Acknowledgements: We would like to thank all the participants for their co-operation and also acknowledge The Indian Council of Medical Research for giving us an opportunity to carry out this project under the Short Term Studentship (STS) 2013.

COMPETING INTERESTS: no support from any organization for the submitted work; no financial relationships with any organizations that might have an interest in the submitted work in the previous three years; no other relationships or activities that could appear to have influenced the submitted work.

FUNDING: As this research project is a part of ICMR STS 2013, the student has received an amount of Rs10,000 INR as scholarship. This study's funder played no role in study design; in the collection, analysis, and interpretation of data; in the writing of the report; and in the decision to submit the article for publication. The researchers were independent from the funders. Any Short Term Student (STS) Project of ICMR are permitted for publication as per their rules with due acknowledgement to them.

DATA SHARING: "No additional data available".

\section{References}

1. GLOBOCAN 2008: Cancer Incidence and Mortality Worldwide. Lyon, France: International Agency for Research on Cancer, WHO. www.globocon 2008. Accessed on 17.11.2012.
2. D'Souza ND, Murthy NS, Aras RY. Projection of cancer incident cases for India-till 2026. Asian Pac J Cancer Prev. 2013;14(7):4379-86.

http://dx.doi.org/10.7314/APJCP.2013.1

4.7.4379 PubMed PMID: 23992007.

3. Divaker H. Knowledge and awareness about preventive health seeking behaviour and acceptability of cervical cancer vaccine in urban women in comparison with school students. Journal of South Asian Federation of Obstetrics and Gynaecology. 2012 JanApr;4(1):47-53.

4. Murthy NS, Mathew A. Cancer epidemiology, prevention and control. Current science. 2004 Feb; 86(4): 51827.

5. Bastos J, Peleteiro B, Gouveia J, Coleman MP, Lunet N. The state of the art of cancer control in 30 European countries in 2008. Int J Cancer. 2010 Jun 1;126(11):2700-15. doi: 10.1002/ijc.24963. PubMed PMID: 19830695.

6. Levi F, Lucchini F, Negri E, Franceschi $S$, la Vecchia C. Cervical cancer mortality in young women in Europe: patterns and trends. Eur J Cancer. 2000 Nov;36(17):2266-71. http://dx.doi.org/10.1016/S09598049(00)00346-4 PubMed PMID: 11072218.

7. Hyacinth HI, Adekeye OA, Ibeh JN, Osoba T. Cervical cancer and pap smear awareness and utilization of pap smear test among Federal civil servants in North Central Nigeria. PLoS One. 2012;7(10):e46583. doi: 10.1371/journal.pone.0046583. Epub 2012 Oct 1. PubMed PMID: 23049708

8. Murthy NS, Mathew A. Screening for cancer of uterine cervix and approaches adopted in India. Indian J Cancer. 1999 Jun-Dec;36(2-4):154-62. PubMed PMID: 10921220. 
9. Tang TS, Solomon LJ, Yeh CJ, Worden JK. The role of cultural variables in breast self-examination and cervical cancer screening behavior in young Asian women living in the United States. J Behav Med. 1999 Oct;22(5):419-36. http://dx.doi.org/10.1023/A:1018653306 776 PubMed PMID: 10586380.

10. Woo JS, Brotto LA, Gorzalka BB. The role of sexuality in cervical cancer screening among Chinese women. Health Psychol. 2009 Sep;28(5):598604. doi: 10.1037/a0015986. PubMed PMID: 19751086.

11. Basu $P$, Sarkar $S$, Mukherjee $S$, Ghoshal M, Mittal S, Biswas S, Mandal R, Sankaranarayanan R. Women's perceptions and social barriers determine compliance to cervical screening: results from a population based study in India. Cancer Detect Prev. 2006;30(4):369-74. Epub 2006 Sep http://dx.doi.org/10.1016/j.cdp.2006.07.0 04 PubMed PMID: 16963194.

12. Selected planning frameworks, social science theories, and models of change. Appendix B In: Making health communication programs work. Bethesda, MD: United States Department of Health and Human Services: Public Health Services: National Cancer Institute; 2008. p. 217226.

13. Schiavo R. Health communication: from theory to practice. 1st ed. San Francisco: Jossey-Bass; 2007. 